\title{
Kynurenic acid, an IDO metabolite, controls TSG-6-mediated immunosuppression of human mesenchymal stem cells
}

\author{
Guan Wang ${ }^{1} \cdot$ Kai Cao ${ }^{1} \cdot$ Keli Liu ${ }^{1} \cdot$ Yueqing Xue ${ }^{1} \cdot$ Arthur I. Roberts $^{2} \cdot{\text { Fengying } \mathrm{Li}^{1} \cdot \text { Yanyan Han }}^{1} \cdot$ \\ Arnold B. Rabson ${ }^{2} \cdot$ Ying Wang ${ }^{1} \cdot$ Yufang Shi $\mathbb{1}^{1,3}$
}

Received: 11 July 2017 / Revised: 30 September 2017 / Accepted: 2 October 2017 / Published online: 13 December 2017

(c) The Author(s) 2018. This article is published with open access

\begin{abstract}
Mesenchymal stem cells (MSCs) have been demonstrated to be anti-inflammatory against various immune disorders through several factors, including indoleamine 2,3-dioxygenase (IDO) and TNF-stimulated gene 6 (TSG-6). However, little is known about the necessity for both of these key immunosuppressive factors. Here we employed the mouse lipopolysaccharide (LPS)-induced acute lung injury (ALI) model, and found that IDO is necessary to achieve the effect of human umbilical cord-derived MSC (hUC-MSC)-based treatment on ALI. Notably, when IDO was deleted or inhibited, the expression of TSG-6 was decreased. This specific IDO-mediated regulation of TSG-6 expression was found to be exerted through its metabolite, kynurenic acid (KYNA), as inhibition of KYNA production led to decreased TSG-6 expression. Importantly, KYNA pretreatment of human MSCs enhanced their therapeutic effect on ALI. Mechanistically, KYNA activates aryl hydrocarbon receptor (AhR), which directly binds to the TSG-6 promoter to enhance TSG-6 expression. Therefore, our study has uncovered a novel link between IDO and TSG-6, and demonstrates that a metabolite of IDO controls the TSG-6mediated anti-inflammatory therapeutic effects of human MSCs.
\end{abstract}

Edited by H.-U. Simon

Electronic supplementary material The online version of this article (https://doi.org/10.1038/s41418-017-0006-2) contains supplementary material, which is available to authorized users.

Ying Wang

yingwang@sibs.ac.cn

$\triangle$ Yufang Shi

yfshi@suda.edu.cn

1 Key Laboratory of Stem Cell Biology, Institute of Health Sciences, Shanghai Institutes for Biological Sciences, Chinese Academy of Sciences/Shanghai Jiao Tong University of Medicine; University of Chinese Academy of Sciences, 320 Yueyang Road, Shanghai 200031, China

2 Child Health Institute, Robert Wood Johnson Medical School, Rutgers the State University of New Jersey, 89 French Street, Piscataway, NJ 08901, USA

3 The First Affiliated Hospital of Soochow University and Key Laboratory of Stem Cells and Biomedical Materials of Jiangsu Province and Chinese Ministry of Science and Technology, Institutes for Translational Medicine, Soochow University, 199 Renai Road, Suzhou 215123, China

\section{Introduction}

Mesenchymal stem cells (MSCs) are a population of heterogeneous stem cells that exist in almost all tissues, and are capable of differentiating into certain cell types $[1,2]$. It is evident that the salutary effects of exogenously administrated MSCs on tissue repair arise from their immunoregulatory effect, a function that is licensed by inflammation [2-5]. A series of factors and molecules produced by human MSCs, like IDO and TSG-6, have been shown to be critical for their immune-regulating function [4]. This variability in the immunosuppressive factors and mechanisms is likely a consequence of the differences in the tissue types and microenvironments in which the MSCs reside.

Previous studies have demonstrated an indispensable role for indoleamine 2,3-dioxygenase (IDO) in the immunomodulatory capacity of human MSCs [6-9]. This enzyme catalyzes the first and rate-limiting step of tryptophan catabolism along the kynurenine pathway, and IDO and several of its downstream metabolites, including kynurenine (KYN) and 3-hydroxyanthranilic acid, not only inhibit effector T-cell proliferation, but also induce the differentiation of regulatory T cells (Treg) [10-12]. Notably, IDO has been shown to regulate inflammation-associated gene 
Fig. 1 IDO insufficiency impairs therapeutic effect of hUC-MSCs on a mouse model of acute lung injury. a HUC-MSCs were transfected with IDO shRNA (IDO-KD) or control (ctrl) scramble shRNA. Cells were then treated with IFN- $\gamma$ and TNF- $\alpha$ (I + T, $10 \mathrm{ng} / \mathrm{ml}$ each) for $24 \mathrm{~h}$. Western blotting analysis revealed effective IDO knockdown (inserts). Acute lung injury was induced by LPS administration. IDO-KD MSCs or control cells $\left(2.5 \times 10^{5}\right)$ were pretreated with IFN- $\gamma$ and TNF$\alpha$ for $48 \mathrm{~h}$, and injected i.v. into $\mathrm{Balb} / \mathrm{c}$ mice 4 and $28 \mathrm{~h}$ after LPS administration. After 2 days, BAL fluid was obtained and total cell number was determined. b Neutrophil cell number in BAL fluid was determined. Bars indicate mean \pm SEM. $* P<0.05$, $* * P<0.01$. c, d Lung tissues after the various treatments were fixed for H\&E staining (c) or specifically stained Gr-1 using immunohistochemistry (d). Images are representative for each group. Three animals were included in each group and similar results were obtained in repeats (scale bars, $50 \mu \mathrm{m}$ )
A

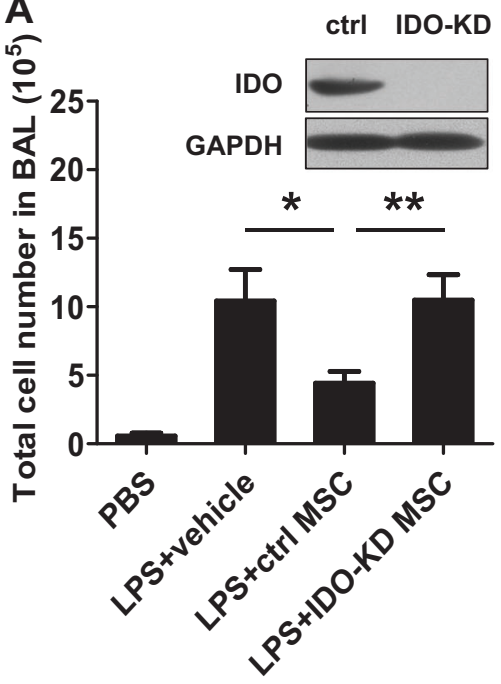

C

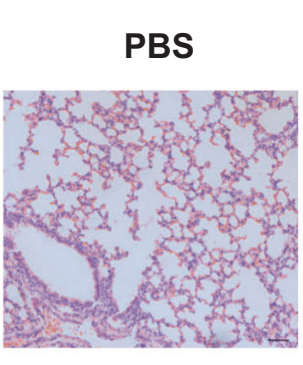

D

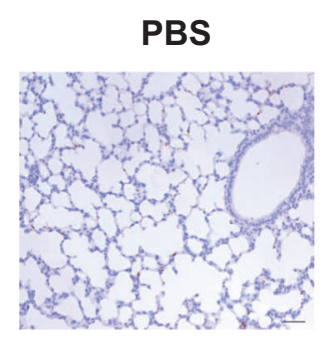

B

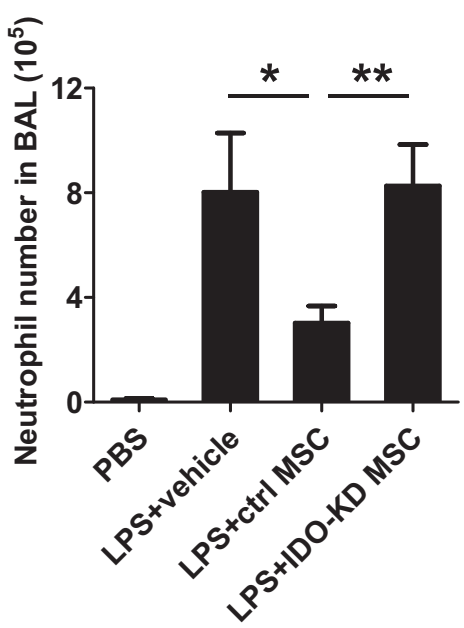

LPS

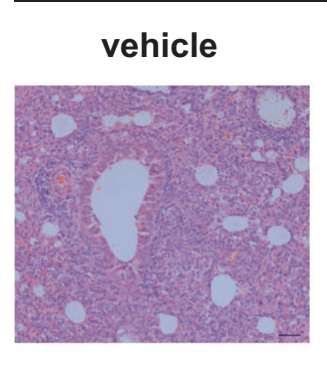

ctrl MSC

IDO-KD MSC
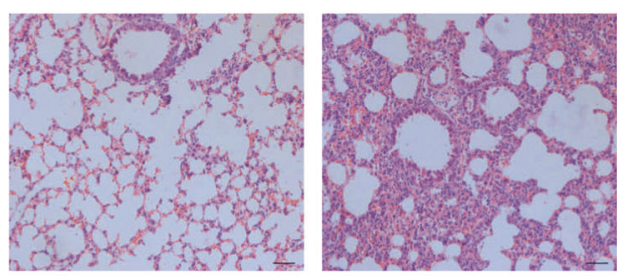

LPS

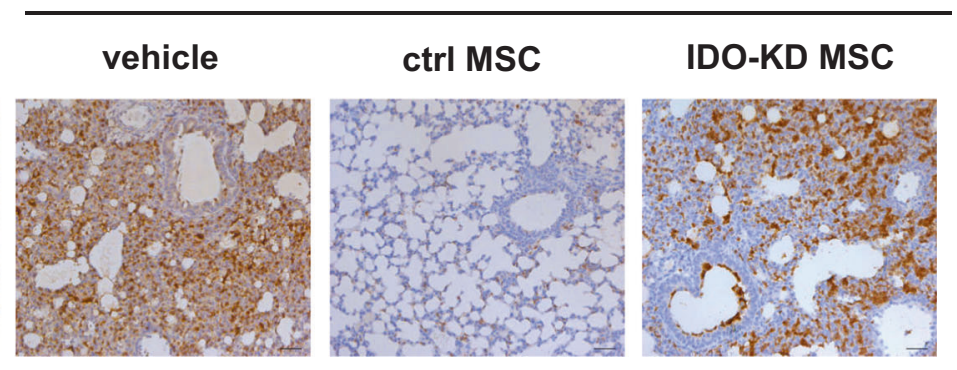

expression, either by itself as a signaling factor, or through the generation of bioactive intermediates via the kynurenine pathway, such as 3-hydroxyanthranilic acid and kynurenic acid (KYNA) [12-14].

TSG-6, a 30-kDa glycoprotein, is another crucial factor that plays a major role in the tissue repair function exerted by human MSCs such as that demonstrated in mouse models of myocardial infarction, peritonitis, and acute corneal and lung injury [15-18]. TSG-6 is a secreted protein that could modulate the extracellular matrix by binding to serine protease inhibitor inter- $\alpha$-inhibitor and glycosaminoglycans (GAGs) [19]. Through its interaction with the GAG-binding site of CXCL8, it antagonizes the association of CXCL8 with heparin, thus inhibiting CXCL8-mediated chemotaxis by neutrophils [20]. Moreover, it has been reported to inhibit the extravasation of leukocytes, mainly neutrophils and macrophages, at sites of inflammation $[15,21]$.

Despite the well-recognized role of these human MSC-expressed factors in immunomodulation, their relationship and function in immunoregulation by MSCs is unclear. In the present study, we found that IDO in MSCs controls TSG-6 expression and its indispensable roles in restriction of leukocyte extravasation in inflammatory diseases. Detailed analysis demonstrated that IDO metabolite, KYNA, specifically regulates TSG6 production by activating aryl hydrocarbon receptor (AhR). More importantly, KYNA-pretreated MSCs can further boost TSG-6 production and thus enhance the therapeutic capacity of human MSCs against lipopolysaccharide (LPS)-induced acute lung injury (ALI). 
Fig. 2 IDO knockdown suppresses TSG-6 production by hUC-MSCs. a IDO-KD MSCs and control cells were treated with IFN- $\gamma$ and TNF- $\alpha$ (10 ng/ $\mathrm{ml}$ each) for $24 \mathrm{~h}$ and levels of TSG-6 mRNA (left) and protein (right) were examined by realtime PCR and ELISA of the culture supernatant, respectively. b, c Similarly, Ang-1 (b) and KGF (c) mRNA levels were measured in these cells. All sample transcript levels were normalized to the level of housekeeping gene $\beta$-actin, and the relative levels were calibrated to the ctrl value. Bars indicate mean \pm SEM. $* P<0.05$ based on a Student's $t$-test. All graphs show the average of three independent repeats, unless otherwise noted

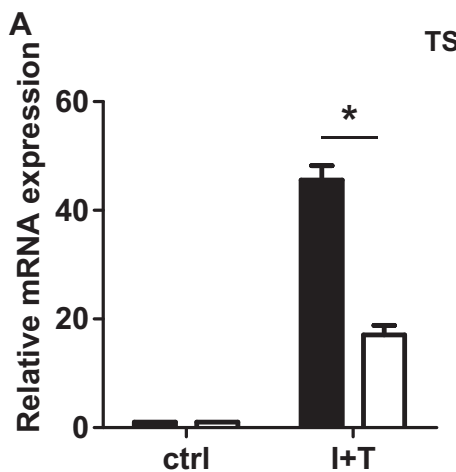

TSG-6

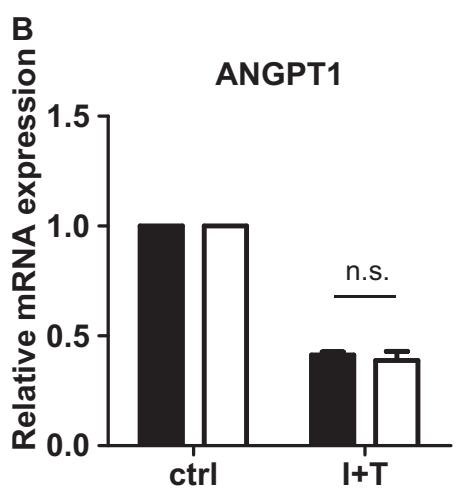

C
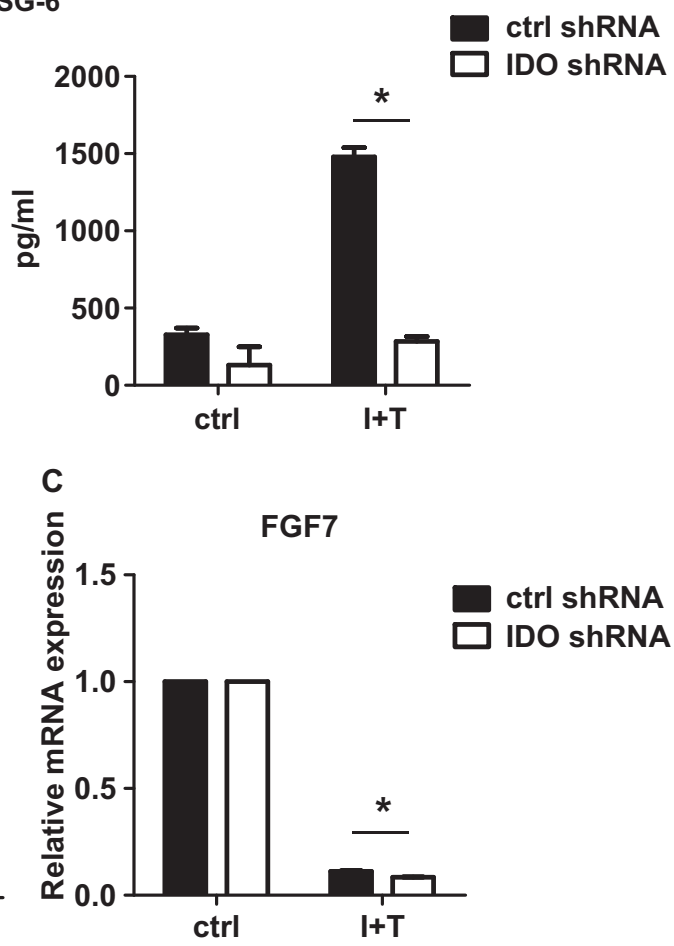

Therefore, our study reveals a novel link between IDO and TSG-6 in human MSCs, a finding that will allow better optimization of MSC-based clinical treatments for inflammatory conditions.

\section{Results}

\section{IDO is critical for MSC-based treatment of LPS- induced $A L I$}

MSCs are normally benign and their immunosuppressive capability relies on their license by a combination of inflammatory cytokines, interferon- $\gamma$ (IFN- $\gamma$ ), and tumor necrosis factor- $\alpha$ (TNF- $\alpha$ ). Various factors have been demonstrated to mediate MSC-based immunosuppression in both in vivo and in vitro experimental systems [22]. Among them, IDO is pivotal in mediating the suppressive effect of human MSCs on adaptive immune responses, since blockade of IDO expression or its function in human MSCs can disrupt their immunosuppressive function [6,7]. Yet, little is known about its role of IDO in MSC-based regulation of innate immune response, especially in in vivo settings. To address this, we firstly employed MSCs derived from human umbilical cord (hUC-MSCs; Supplementary Fig. 1), and established stable IDO knockdown (IDO-KD) cell line using lentivirus transfection (Fig. 1a). Next, we employed the LPS-induced ALI model in BALB/c mice through intranasal administration of LPS. These mice showed increased number of total cells and neutrophils in the bronchoalveolar lavage (BAL) fluid at $48 \mathrm{~h}$ after LPS administration (Figs. 1a, b). Their lung histology also exhibited widespread septal thickening, significant increases in air-space cellularity and exudation, and significant interstitial immune cell infiltration (Fig. 1c). Using this model we examined the therapeutic effect of control MSCs and IDOKD MSCs. After pretreatment with IFN- $\gamma$ and TNF- $\alpha$, MSCs were injected intravenously after LPS administration. As expected, administration of control MSCs resulted in significant alleviation of lung inflammation, as indicated both by cell number in BAL fluid and hematoxylin and eosin (H\&E) staining of lung tissue sections. In contrast, when IDO-KD MSCs were used, the inflammatory status was unaffected compared to control group, indicating that IDO is important in mediating the therapeutic role of MSCs (Figs. 1a-c). To further confirm the role of IDO on the infiltration of neutrophils, we next performed immunohistological staining for Gr-1, a well-known marker of neutrophils. As expected, decreased neutrophil infiltration was found in control MSC-treated mice, while IDO-KD MSC treatment abolished this effect (Fig. 1d). Thus, our results demonstrate that IDO is indispensable in the therapeutic effect of human MSCs on mouse ALI.

\section{IDO acts by regulating the expression of TSG- 6 by MSCs}

Several factors, including fibroblast growth factor 7 (FGF7, also known as KGF), angiopoietin 1 (ANGPT1, also known as Ang-1), TSG-6, and interleukin 1 receptor antagonist 
(IL-1R $\alpha$ ), have been demonstrated to mediate the therapeutic function of MSCs in ameliorating ALI through various mechanisms [16, 23-25]. As IDO is critical in the therapeutic effect of MSCs on ALI, we next examined whether this effect is exerted through regulating the expression of any of these molecules. We first checked the expression profile of these factors in IDO-KD cells. We found that TSG-6 production was dramatically inhibited in IDO-KD MSCs on both the mRNA and protein levels (Fig. 2a). To exclude any off-target effect, we also performed small interfering RNA (siRNA) transfection to knockdown IDO and found that TSG-6 expression was similarly reduced (Supplementary Fig. 2). These data suggested that IDO could regulate TSG-6 expression in MSCs. Interestingly, when we looked at the expression of other molecules, we found that the expression levels of Ang-1 or KGF were unaffected (Figs. 2b, c), and IL-1R $\alpha$ expression was not detectable (data not shown). Therefore, the regulatory effect of IDO on TSG-6 is specific, and it is possible that IDO-mediated therapeutic effect of MSCs on ALI is exerted through TSG-6.

To test this, TSG-6-knockdown (TSG-6-KD) MSCs were established by similar lentivirus transfection (Fig. 3a). We next employed this cell line and recombinant human TSG-6 protein (rhTSG-6) to verify the role of TSG-6. After the treatment of exogenous rhTSG-6, we found that ALI was significantly alleviated, as evidenced by reduced number of infiltrated immune cells, specifically neutrophils, in the lung. In contrast, TSG-6-KD MSCs had little therapeutic effect (Figs. 3a-d). These data suggest that IDO expressed by MSCs alleviates ALI through regulating the expression of TSG-6. To further verify the role of TSG-6, we co-inject IDO-KD MSCs with rhTSG-6 to ALI mice, and found that the effect of IDO-KD MSCs was completely rescued by rhTSG-6 (Supplementary Fig. 3). To verify whether this relationship between IDO and TSG-6 also exists in other diseases mediated by innate immunity, we next established zymosan-induced peritonitis model, which has been reported to respond to human MSC treatment through secretion of TSG-6 as well [15]. We performed similar treatment and, as expected, the therapeutic effect of control MSCs was impaired in this peritonitis model when the expression of either IDO or TSG-6 was compromised. In addition, not only neutrophil, but also macrophage infiltration was regulated in a similar pattern (Supplementary Fig. 4). Collectively, our in vivo results demonstrate that the therapeutic effects of human MSCs in certain inflammatory diseases is exerted through IDO-regulated TSG-6 expression, implicating a regulatory role of IDO on the production of TSG-6 by MSCs.

Given the potential regulatory effect of IDO on TSG-6, we investigated whether TSG-6 could in turn influence the expression of IDO by MSCs. When we measured the expression of IDO by cytokine-activated TSG-6-KD MSCs, we found that the absence of TSG-6 did not affect IDO expression (Supplementary Fig. 5A). Furthermore, when we examined the IDO-mediated immunosuppressive effect of MSCs on T cells, we found that, compared to control MSCs, IDO-KD MSCs lost their ability to inhibit T cells as expected, and TSG-6-KD MSCs could still significantly suppress T-cell proliferation in vitro. This confirmed that TSG-6 has no effect on IDO expression and the subsequent suppression of $\mathrm{T}$ cells (Supplementary Fig. 5B). Of note, TSG-6 is itself immunosuppressive, and it acts by regulating the extracellular matrix $[20,21]$. Thus, it is difficult to accurately measure the function of TSG-6 in an in vitro system. Taken together, these results show that IDO is the critical factor in controlling the production of TSG-6 in human MSCs.

\section{IDO metabolite KYNA controls the production of TSG-6 by MSCs}

IDO has been reported to regulate gene expression either as a signaling factor or by its production of metabolites with gene-regulatory functions [12-14]. To explore the mechanisms underlying the regulatory effect of IDO on TSG-6, we employed an IDO enzymatic inhibitor, 1methyltryptophan (1-MT), which only inhibits the catalytic capability of IDO without affecting its expression (Fig. 4a). Interestingly, 1-MT treatment was also found to dramatically reduce TSG- 6 mRNA and protein levels, suggesting that IDO regulates the production of TSG-6 through its enzymatic activity, not as a signaling factor (Fig. 4b).

As demonstrated, IDO metabolites of tryptophan, including kynurenine (KYN), KYNA, and 3hydroxyanthranilic acid, are immunosuppressive and can regulate gene expression [11-13]. Since the enzymatic activity of IDO is critical in regulating TSG-6, we next examined the production of the main tryptophan metabolites, which can be inferred by the levels of several key enzymes that strictly control tryptophan metabolism in hUC-MSCs [26]. Surprisingly, among all these enzymes tested, only kynurenine aminotransferase II (KAT II), which mediates the catalysis of KYN to KYNA, was found to be highly expressed in hUC-MSCs, indicating that KYN and KYNA might be the main tryptophan metabolites (Fig. 4c). Indeed, when examining the concentration of all possible tryptophan metabolites in hUC-MSC supernatant by highperformance liquid chromatography (HPLC), we found that only KYN and KYNA were abundantly produced (Fig. 4d). Next, to explore whether any of these two molecules can affect TSG-6 expression by hUC-MSCs, we treated MSCs with KYN or KYNA, and examined the expression TSG-6. We found that only KYNA-treated MSCs exhibited higher levels of TSG-6, compared to untreated controls (Fig. 4e). The effect of KYNA on TSG-6 expression was further confirmed by the finding that siRNA inhibition of KAT II, 
A

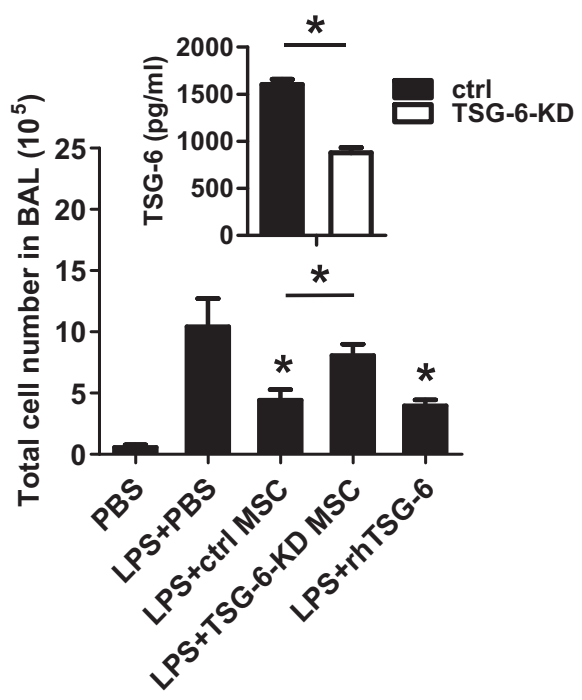

B

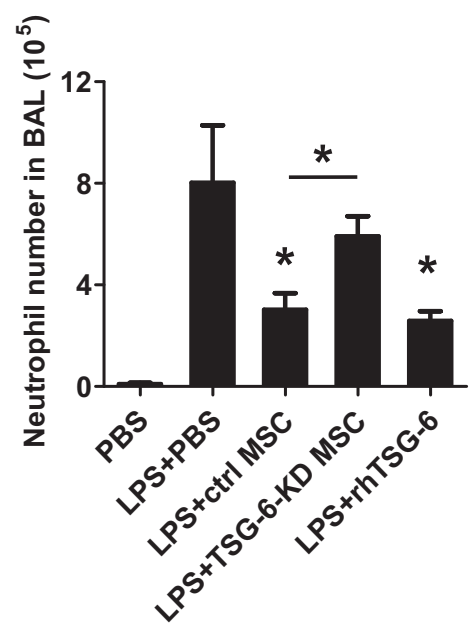

C

LPS

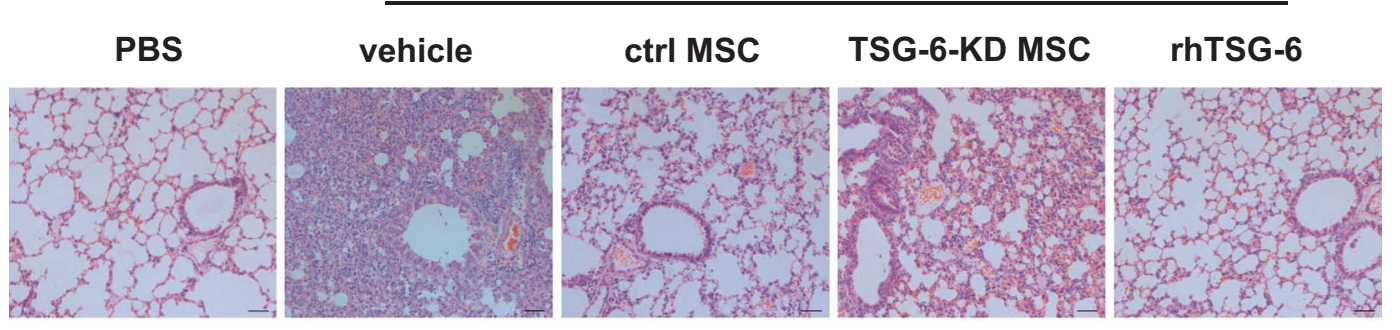

D

LPS

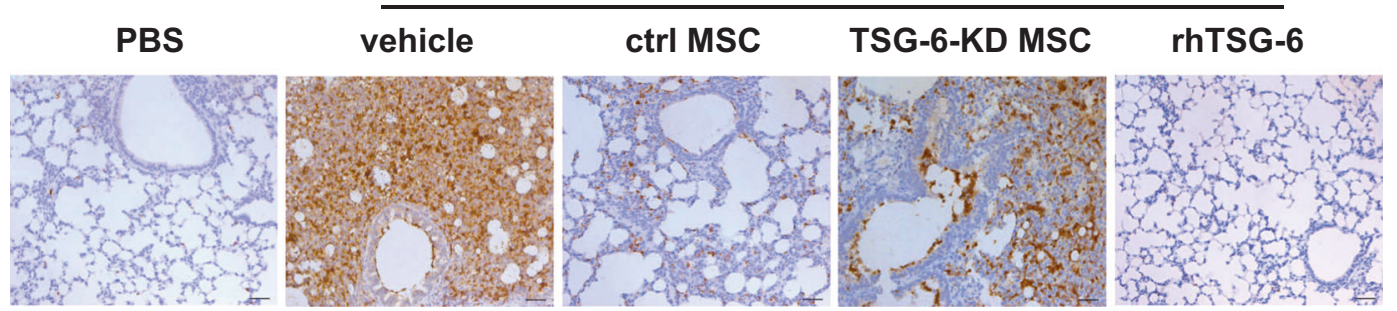

Fig. 3 The therapeutic effect of hUC-MSCs on acute lung injury occurs through TSG-6. a HUC-MSCs transfected with TSG-6 shRNA (TSG-6-KD) or control (ctrl) scramble shRNA were examined for TSG-6 production. These cells were then treated with IFN- $\gamma$ and TNF$\alpha(10 \mathrm{ng} / \mathrm{ml}$ each $)$ for $24 \mathrm{~h}$ and the supernatant was assayed using ELISA (inserts). All graphs show the average of three independent repeats, unless otherwise noted. TSG-6-KD MSCs and control cells were pretreated with IFN- $\gamma$ and TNF- $\alpha(10 \mathrm{ng} / \mathrm{ml}$ each $)$ for $48 \mathrm{~h}$ and

resulted in decreased concentration of both KYNA and TSG-6 in the MSC supernatant (Figs. 4f-h). Therefore, IDO promotes the expression of TSG-6 through the production of KYNA, a tryptophan metabolite.

\section{KYNA-treated MSCs significantly alleviate neutrophil infiltration in ALI}

Given that KYNA promotes the production of TSG-6 by MSCs, we next examined whether KYNA-treated MSCs these cells $\left(2.5 \times 10^{5}\right.$ per mouse $)$ or rhTSG-6 protein $(25 \mu \mathrm{g})$ were injected as in Fig. 1. Total cell number in BAL fluid was determined, as in Fig. 1. b Neutrophil number in BAL fluid was determined as in Fig. 1. Bars indicate mean \pm SEM. $* P<0.05$. c, $\mathbf{d}$ Lung tissues were fixed for H\&E staining (c) and for Gr-1-specific immunohistochemistry (d). Images are representative for each group. Three animals were included in each group and similar results were obtained in repeats (scale bars, $50 \mu \mathrm{m}$ )

could alleviate ALI in vivo. Accordingly, MSCs were pretreated with IFN- $\gamma$ and TNF- $\alpha$ in the presence or absence of KYNA, and their therapeutic effects were observed. As expected, the number of infiltrated cells, as well as that of infiltrated neutrophils, was significantly decreased in the lung of the mice injected with KYNA-pretreated MSCs, indicating that KYNA could promote the therapeutic effect of MSCs in treating ALI (Figs. 5a, b). Furthermore, H\&E staining and Gr-1 immunohistological staining also revealed reduced inflammatory responses, including less neutrophil 

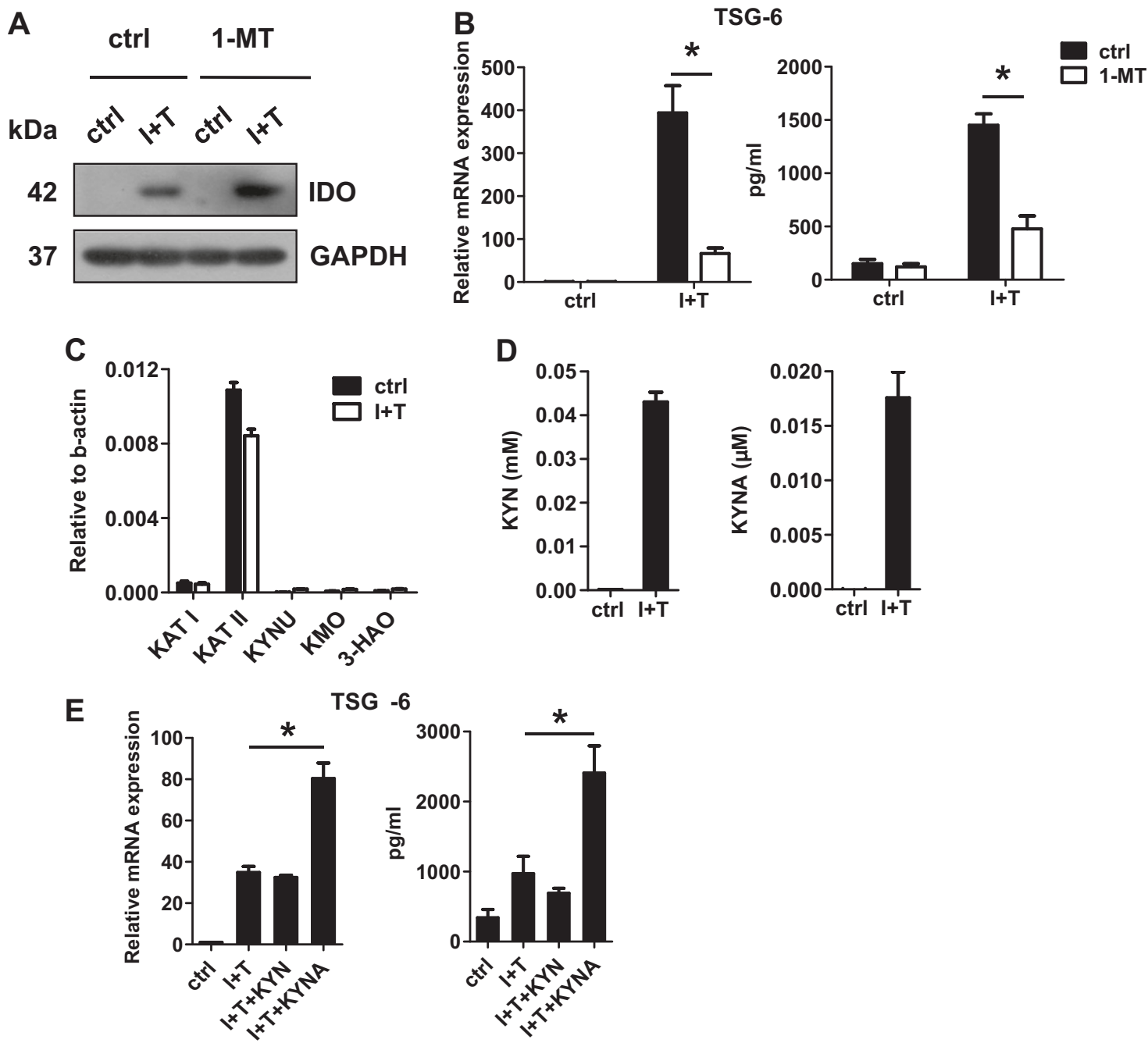

TSG -6

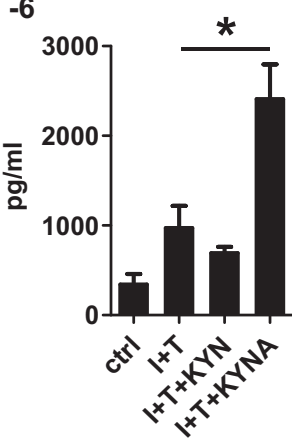

$\mathbf{F}$
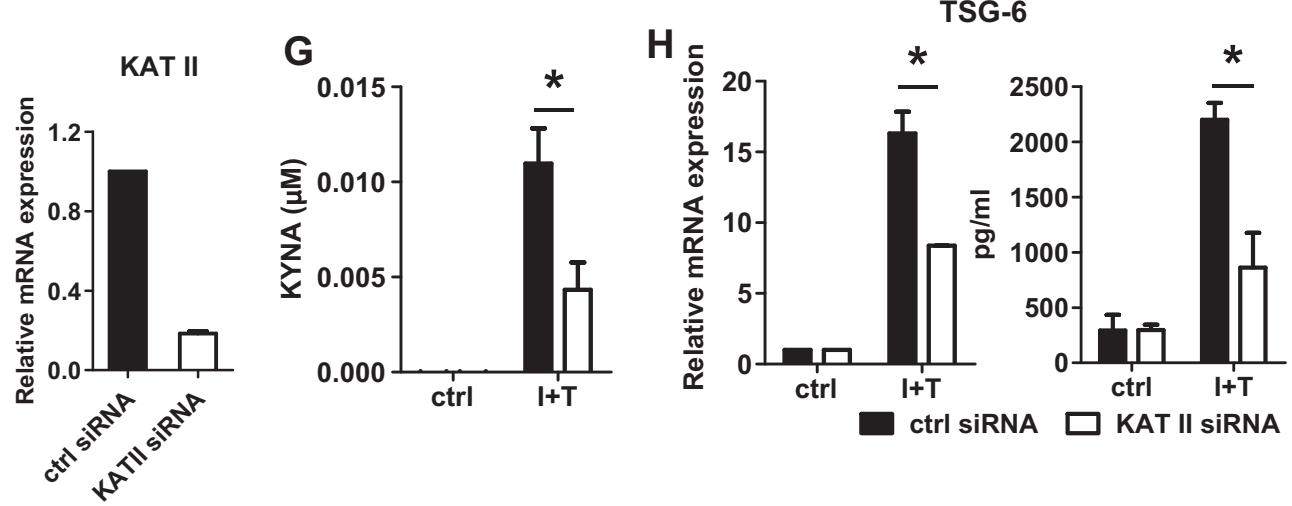

Fig. 4 IDO metabolite KYNA promotes TSG-6 production in hUC-MSCs. a HUC-MSCs were treated with IFN- $\gamma$ and TNF- $\alpha$ (10 ng/ml each) with or without 1-MT $(0.5 \mathrm{mM})$ for $24 \mathrm{~h}$. Cells were collected and IDO level was revealed by western blot. b HUC-MSCs were treated as in (a), and then the production of TSG-6 mRNA (left) and protein (right) was examined. c HUC-MSCs treated with IFN- $\gamma(1 \mathrm{ng} / \mathrm{ml})$ and TNF- $\alpha$ (10 ng/ml) for $24 \mathrm{~h} \mathrm{were}$ examined for their expression of enzymes in the kynurenine pathway by real-time PCR. Transcript levels were normalized to the levels of housekeeping gene $\beta$-actin. KAT I kynurenine aminotransferase I, KAT II kynurenine aminotransferase II, KYNU kynureninase, KMO kynurenine 3-monooxygenase, 3$H A O$ 3-hydroxyanthranilate 3,4-dioxygenase. d KYN and KYNA concentrations in supernatant from cells treated as in (c) were assayed using HPLC-MS. e HUC-MSCs treated with IFN- $\gamma(1 \mathrm{ng} / \mathrm{ml})$ and TNF- $\alpha(10 \mathrm{ng} / \mathrm{ml})$ with or without KYN $(200 \mu \mathrm{M})$ or KYNA $(50 \mu \mathrm{M})$ for $24 \mathrm{~h}$ were tested for their expression of TSG-6 mRNA (left) and protein (right). f, $\mathbf{g}$ HUC-MSCs were transfected with KAT II siRNA, and knockdown efficiency was examined by real-time PCR of KAT II expression (f) and HPLC-MS analysis of KYNA in the supernatant (g). h KAT II-KD MSCs and control cells were treated with or without IFN- $\gamma(1 \mathrm{ng} / \mathrm{ml})$ and TNF- $\alpha(10 \mathrm{ng} / \mathrm{ml})$ for $24 \mathrm{~h}$, and their production of TSG-6 production was examined at mRNA (left) and protein (right) levels. Bars indicate mean \pm SEM. $* P<0.05$ based on a Student's $t$-test 
Fig. 5 Exogenous KYNA enhances the therapeutic effect of hUC-MSCs on acute lung injury. a, b Acute lung injury was induced by LPS, as in Fig. 1. HUC-MSCs were pretreated with IFN- $\gamma(1 \mathrm{ng} / \mathrm{ml})$ and TNF- $\alpha(10 \mathrm{ng} / \mathrm{ml})$ with or without KYNA $(200 \mu \mathrm{M})$ for 48 $\mathrm{h}$, and $2.5 \times 10^{5}$ cells were administered by i.v. injection, as in Fig. 1. Total cell number (a) and neutrophil number (b) in BAL fluid was determined. Bars indicate mean \pm SEM. $* P$ $<0.05$. c, d The lung tissues were stained for $\mathrm{H} \& \mathrm{E}$ (c) and Gr-1 immunohistochemistry (d). Images are representative for each group. Three animals were included in each group and similar results were obtained in repeats (scale bars, $50 \mu \mathrm{m}$ )
A

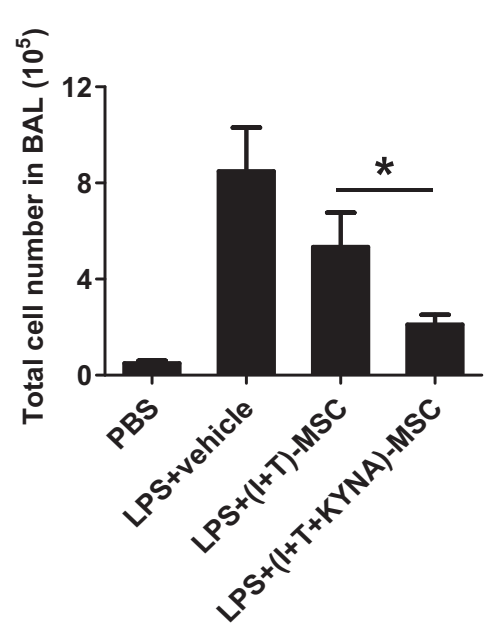

C

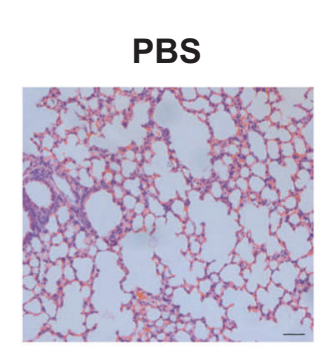

D

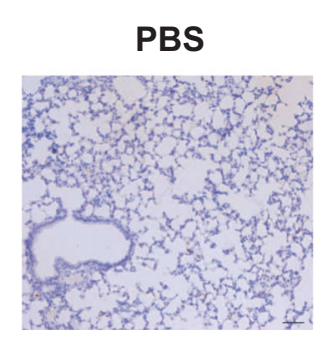

B

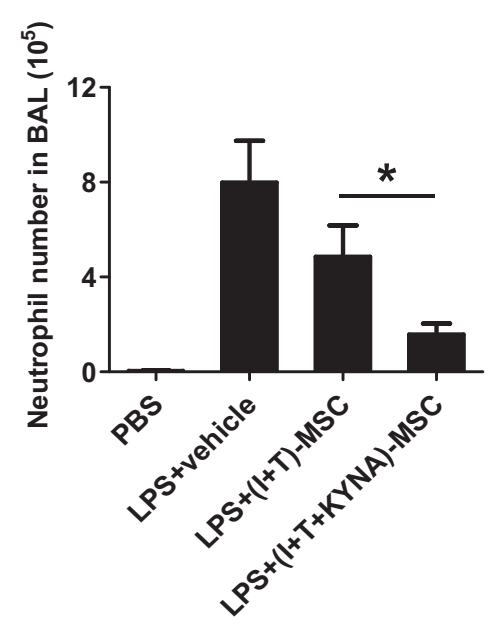

LPS

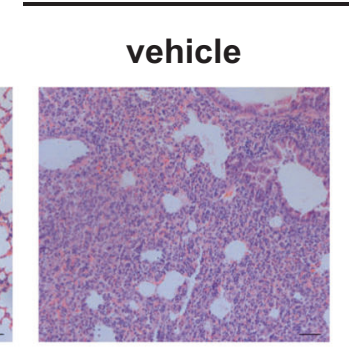

(I+T)-MSC

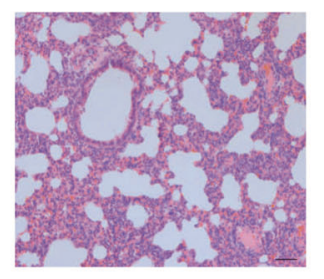

LPS
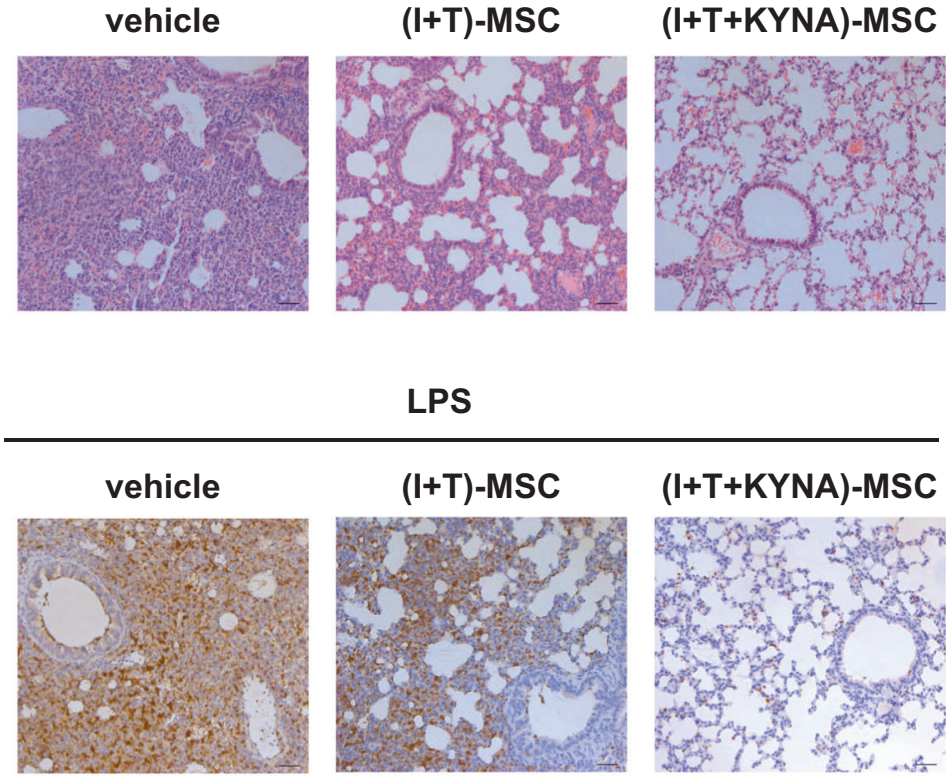

(I+T)-MSC

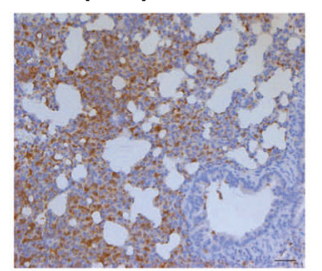

(I+T+KYNA)-MSC

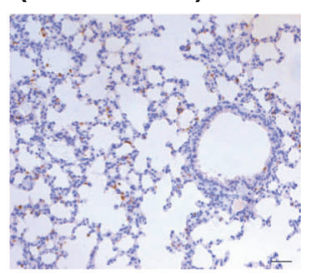

infiltration, in the lungs of mice administered with KYNAtreated MSCs (Figs. 5c, d). Moreover, in the peritonitis model, we found that KYNA could also enhance the therapeutic effect of hUC-MSCs through inhibiting the infiltration of immune cells (Supplementary Fig. 6). Therefore, our in vivo data further confirmed that the IDO metabolite KYNA promotes TSG-6 production by MSCs and, thus, enhance the therapeutic effects of hUC-MSCs in the treatment of inflammatory diseases.

\section{KYNA promotes TSG-6 production through activation of AhR signaling}

KYNA has been reported to have a plethora of receptors [27]. To investigate the detailed mechanism underlying the regulatory effect of KYNA on TSG-6, we first examined the expression of its receptors in human MSCs. Interestingly, we found that MSCs constitutively expressed very high levels of the $A h R$ gene, compared to the expression of other receptors (Fig. 6a). AhR is one of the most recognized member of the basic helix-loop-helix-PER-ARNT-SIM (bHLH-PAS) subgroup of the bHLH superfamily of transcription factors, which is known to be activated by ligands, including dioxin and the IDO-derived metabolites, KYN and KYNA. Upon interaction with ligands, AhR translocates to the nucleus and forms a heterodimer with AhR nuclear translocator (ARNT), which binds to the xenobiotic-responsive element (XRE) sequences, leading to transcription of a wide variety of genes that participate in various cellular processes [28-30]. Therefore, we next 

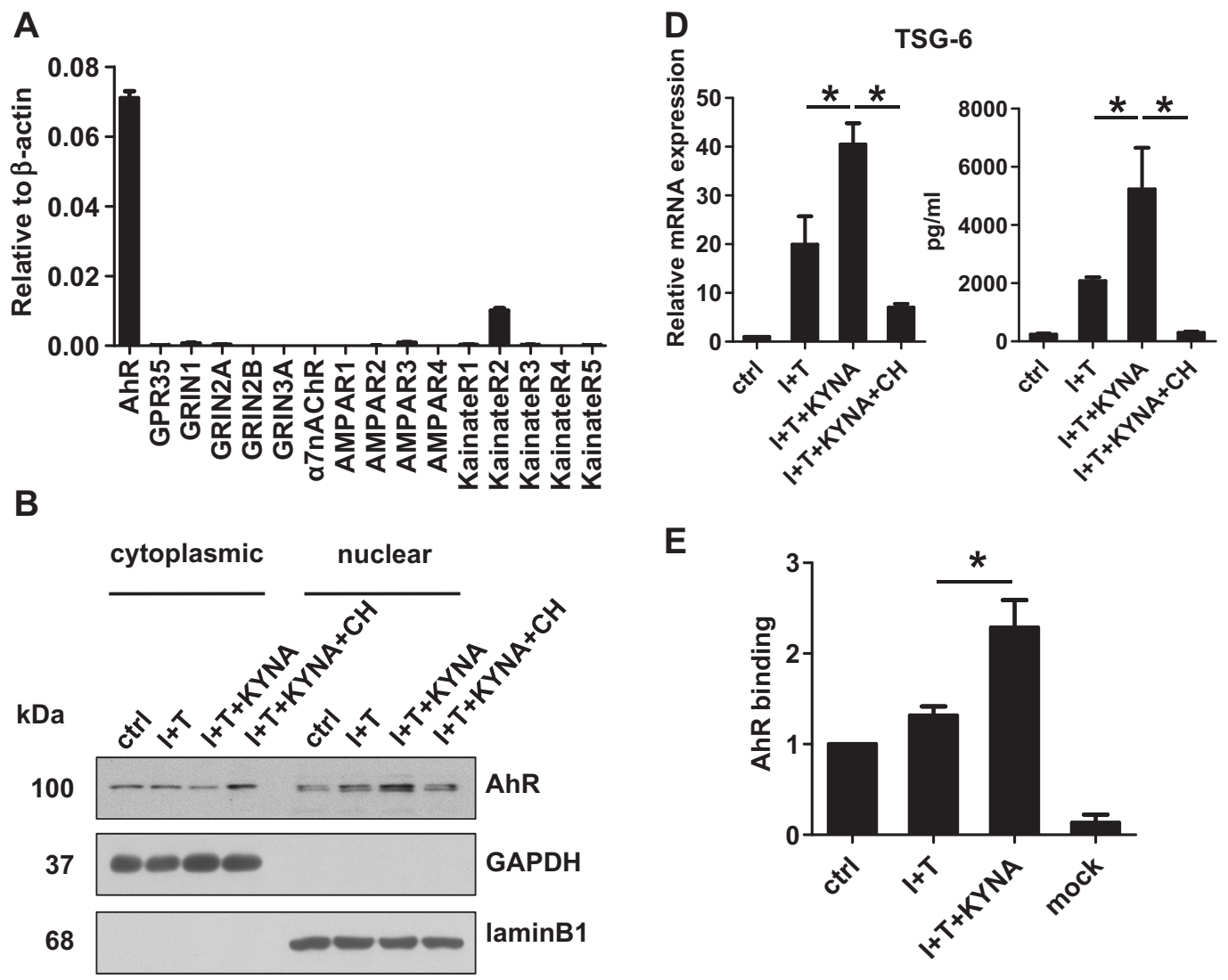

E
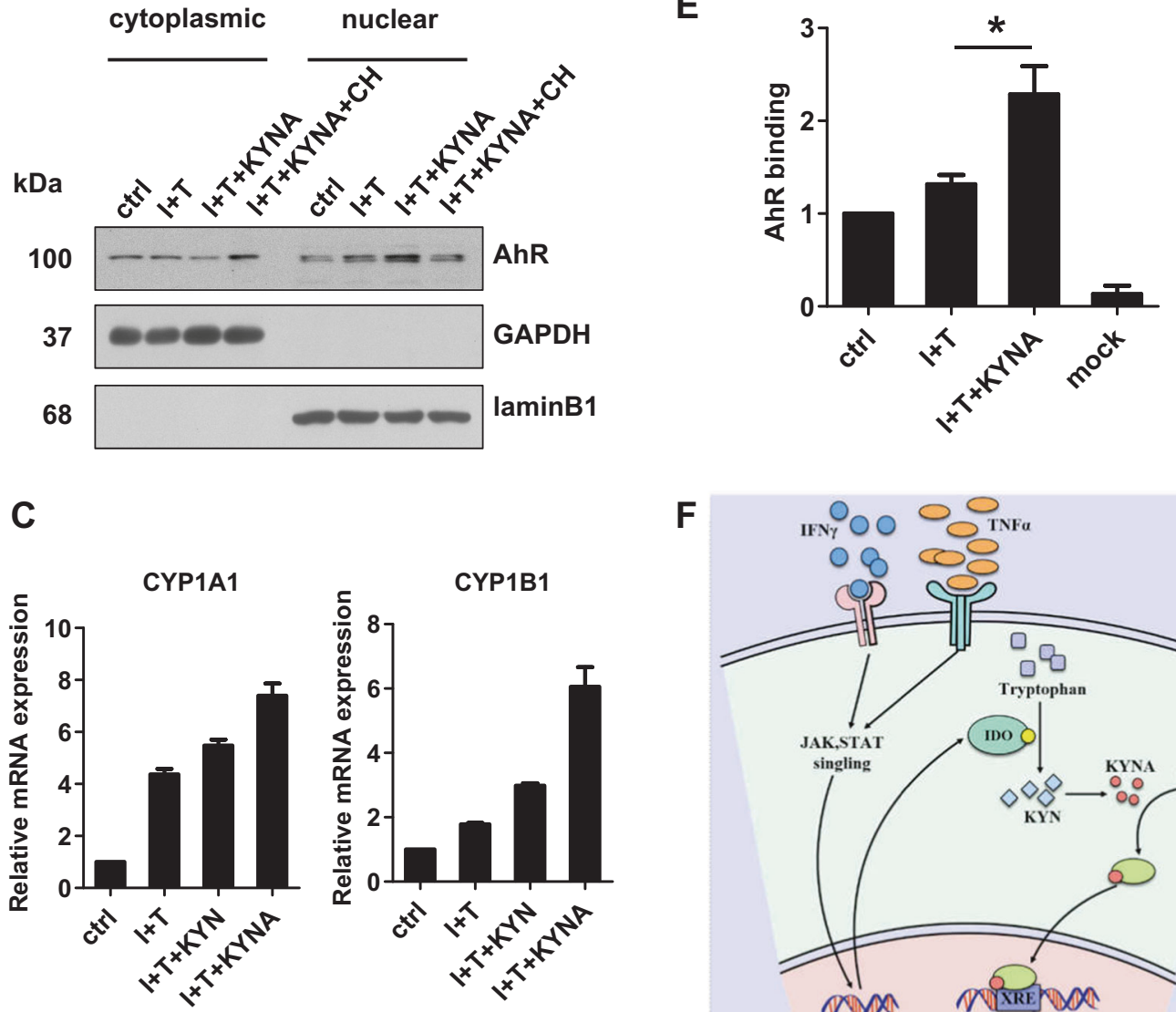

Fig. 6 KYNA activates AhR signaling pathway to enhance TSG-6 production. a HUC-MSCs were examined for the expression of the indicated receptors for KYNA using real-time PCR. Transcript levels were normalized to the levels of housekeeping gene $\beta$-actin. b HUC-MSCs treated with IFN- $\gamma(1 \mathrm{ng} / \mathrm{ml})$ and TNF- $\alpha(10 \mathrm{ng} / \mathrm{ml})$ in the presence or absence of KYNA $(50 \mu \mathrm{M})$ or $\mathrm{CH}-223191(\mathrm{CH}, 20$ $\mu \mathrm{M})$ for $3 \mathrm{~h}$ were subjected to cytoplasmic and nuclear extraction, and the distribution of AhR was analyzed by western blot analysis. GAPDH and laminB1 were served as loading controls for cytoplasmic and nuclear proteins, respectively. c HUC-MSCs were treated with IFN- $\gamma(1 \mathrm{ng} / \mathrm{ml})$ and TNF- $\alpha(10 \mathrm{ng} / \mathrm{ml})$, with or without KYN (200 $\mu \mathrm{M})$ or KYNA $(50 \mu \mathrm{M})$ for $24 \mathrm{~h}$. Cells were then assayed by real-time

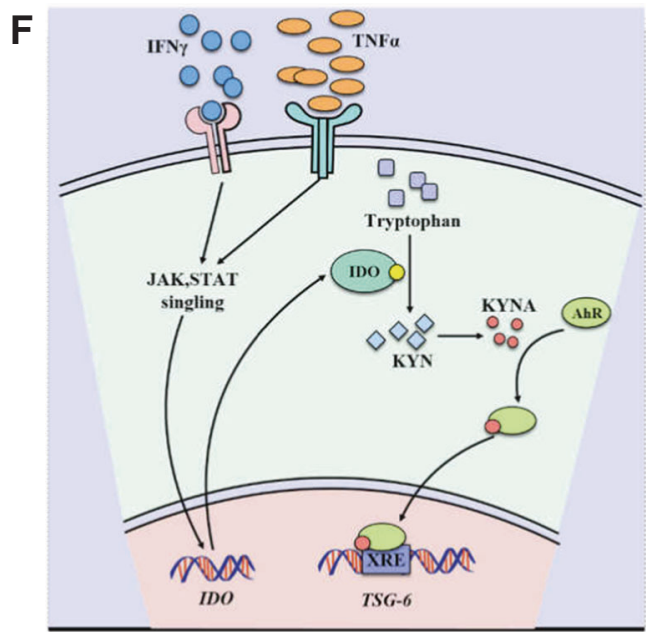

PCR for mRNA expression of CYP1A1 and CYP1B1. d HUC-MSCs were treated with IFN- $\gamma(1 \mathrm{ng} / \mathrm{ml})$ and TNF- $\alpha(10 \mathrm{ng} / \mathrm{ml})$, with or without KYNA $(50 \mu \mathrm{M})$ or $\mathrm{CH}(20 \mu \mathrm{M})$ for $24 \mathrm{~h}$, production of TSG-6 mRNA (left) and protein (right) were examined. e The interaction of AhR with TSG-6 promoter was examined by ChIP analysis. HUC-MSCs treated with IFN- $\gamma(1 \mathrm{ng} / \mathrm{ml})$ and TNF- $\alpha(10 \mathrm{ng} / \mathrm{ml})$, with or without KYNA $(50 \mu \mathrm{M})$ for $3 \mathrm{~h}$ were subjected to ChIP with anti-AhR, and the amount of specific DNA sequence obtained was determined by real-time PCR. "Mock": no antibody added. Bars indicate mean \pm SEM. $* P<0.05$ based on a Student's $t$-test. f The schematic overview of IDO metabolite regulated TSG-6 production in human MSCs 
examined the nuclear translocation of AhR in MSCs treated with KYNA. We found that KYNA treatment significantly increased the translocation of AhR to the nucleus, indicating that KYNA can activate AhR signaling in MSCs (Fig. 6b, Supplementary Fig. 7A). This result is further evidenced by the increased expression of AhR-regulated metabolic enzymes, including CYP1A1 and CYP1B1 (Fig. 6c). Moreover, addition of the specific AhR antagonist $\mathrm{CH}$ 223191, which prevents AhR translocation (Fig. 6b, Supplementary Fig. 7A), abolished the enhanced TSG-6 production by KYNA (Fig. 6d). To determine whether AhR could directly bind to TSG-6 promoter, the TSG-6 promoter was scanned for putative binding site for AhR, revealing one candidate: GTGCTTGAGA (nucleotide -1609 to -1600; Supplementary Fig. 7B). However, no binding sites for AhR were evident in the promoters for $K G F$ or $A n g-1$ (data not shown). Chromatin immunoprecipitation (ChIP) assay was employed to verify the interaction between AhR and the TSG-6 promoter. AhR was found to be able to bind the XRE region of the TSG- 6 promoter, and addition of KYNA enhanced this binding capability (Fig. 6e). Collectively, these results suggest that KYNA indeed acts through its receptor AhR to directly regulate the expression of TSG-6.

\section{Discussion}

Gene expression is controlled at several levels through a variety of mechanisms. In recent years, small molecule metabolites have been increasingly recognized as playing important roles in gene regulation, which is believed to be an essential mechanism that links gene expression with a cell's metabolic state [31, 32]. However, the molecular mechanisms that relay signals from metabolites in the tissue microenvironment to induce an appropriate gene expression response remain poorly understood. A better understanding of the mechanisms connecting metabolic intermediates to specific gene expression would have important ramifications for disease and development. In the present study, we demonstrate that IDO is critical in controlling TSG-6 expression in inflammatory cytokine-primed human MSCs as demonstrated in vivo in our ALI model and peritonitis model. Such regulation relies on the IDO-catalyzed metabolite, KYNA, rather than KYN, catalyzed by IDO. Further mechanistic investigations revealed that KYNA activates AhR to result in its nuclear translocation, thereby directly promoting TSG-6 expression by binding to its promoter (Fig. 6f).

IDO has long been recognized as a metabolic regulator of the immune responses in both MSCs and other immune cell types [9]. By catalyzing the first and rate-limiting step of tryptophan catabolism along the kynurenine pathway, IDO causes consumption of local tryptophan that is essential for proliferating cells, particularly immune cells [9]. Its immunoregulatory effect contributes to immune tolerance in many ways, including cell cycle arrest of proliferating $\mathrm{T}$ cells, long-term tolerance of plasmacytoid dendritic cells, and affecting the process of antigen presentation [14,3335]. On the other hand, by breaking down tryptophan, IDO generates several bioactive intermediates via the kynurenine pathway, including KYN, KYNA, 3-hydroxyanthranilic acid, and quinolinic acid [26]. Increasing evidence indicates that, in addition to the direct cytotoxicity by some of these tryptophan metabolites, they also have various impacts on the immune response [26, 36].

In this study, we found that KYN and KYNA were the two most abundant tryptophan metabolites that are produced by hUC-MSCs. Both molecules have been previously found to regulate immune responses. KYN has been reported to inhibit the proliferation and induce the apoptosis of type 1 helper T cells [10]. It also inhibits natural killer cells, and partially impairs their killing function [10]. In addition, KYN has also been demonstrated to promote the differentiation of Tregs and ameliorate experimental autoimmune encephalomyelitis [11]. In contrast, although it shares the same receptor AhR [13], KYNA differs from KYN in several respects. KYNA has little cytotoxicity, and it may exert distinct impacts in different inflammatory context. In one study, KYNA was found to inhibit IL-10 expression in bone marrow-derived macrophages, and exacerbate atherosclerosis progression [31]. While other studies demonstrated that KYNA exerts an immunosuppressive function by modulating the expression of inflammation-associated genes, such as TNF, IL-6, and matrix metalloproteinases [13, 37, 38]. Given the immunosuppressive functions of KYN and KYNA, it is predictable that modulation of IDO and its downstream metabolites would affect the immunomodulatory role of human MSCs and be beneficial in the treatment of immune disorders.

Although KYN and KYNA share a common receptor AhR, only KYNA can promote TSG-6 production in human MSCs [13]. This might be due to the much higher binding affinity of KYNA for AhR [13]. Indeed, KYNA was effective at much lower concentrations than was KYN, in the induction of AhR-responsive genes in human MSCs (Fig. 6c). However, due to the cytotoxicity of KYN at high concentrations [10, 36], its exact impact on immunomodulation by MSCs awaits further investigation.

Our findings suggest that KYNA-treated MSCs could reduce the number of infiltrating neutrophils in the alveoli of ALI mice. Considering that one important function of TSG-6 is to inhibit neutrophil migration [19, 20], we hypothesized that the mechanism underlying the effectiveness of MSCs in treating ALI was the inhibition of neutrophil extravasation to the lung. Actually, we did observe a 
decrease in CXCL1 and CXCL2 (data not shown), which are the murine homologs of the neutrophil chemokine, CXCL8, in lung extracts from ALI mice treated with human MSCs or recombinant human TSG-6 protein-treated ALI mice. This indicates that TSG-6 competitively binds to chemokine and inhibits their promotion of leukocyte migration. However, it has been difficult to verify TSG-6mediated immunosuppression of neutrophils by human MSCs in vitro, because we found that cytokine-licensed human MSCs secrete, in addition to TSG-6, a large amount of CXCL8, which would dampen the inhibitory function of TSG-6 on neutrophil migration (data not shown). Therefore, whether the alleviating effect of TSG-6 on ALI results from its suppression of neutrophil migration remains to be determined.

We have shown that KYNA pretreatment significantly enhances the therapeutic effect of human MSCs on ALI. ALI and ARDS are major causal factors of mortality in critically ill patients in intensive care unit [39, 40]. However, neither improved intensive clinical care, nor the antiinflammatory drugs or pharmacologic therapies directed at improving lung functions have been effective in reducing mortality over the last several decades [41-49]. In this regard, MSCs have attracted much interest as a potential cell-based treatment for ALI, since preclinical studies have allowed the prospect of curing ALI with MSC therapy [50]. However, a currently clinical study of the effect of allogenic adipose-derived MSCs in ARDS showed only marginal effects, although no adverse side-effect occurred [51]. Therefore, a more effective MSC-based therapeutic strategy is still needed for the treatment of ALI and ARDS patients. Our findings that MSCs can be treated with KYNA to boost their production of TSG-6 and thus prevent neutrophil infiltration may provide a new potential strategy in the treatment of ALI and ARDS.

In summary, in this study we have discovered a novel function of KYNA to directly regulate TSG-6 expression and thus promote TSG-6-mediated immunosuppression by human MSCs. The ability of KYNA to thus promote immunosuppression not only highlights the importance to IDO and its downstream metabolites for their critical roles in cell therapy using MSCs, but also provides a basis for potential new strategies that treats inflammatory diseases through modulating tryptophan metabolism.

\section{Materials and methods}

\section{Isolation and identification of human umbilical cord-derived MSCs}

All procedures were carried out in accordance with the ethical standards of the Ethical Committee of both Changzhou
Maternal and Child Health Care Hospital and Shanghai Institutes for Biological Sciences. With parental consent, umbilical cords from healthy and full-term delivery were obtained and stored in clean glass bottles containing phosphate-buffered saline (PBS), for processing within $4 \mathrm{~h}$ of collection. All were negative for hepatitis B virus, hepatitis C virus, human immunodeficiency virus, sexually transmitted pathogens, and cytomegalovirus. To isolate MSCs, the umbilical cord was washed repeatedly to remove blood using PBS containing penicillin and streptomycin. Then, it minced into $1 \mathrm{~mm}^{3}$ pieces, which were seeded into cell culture flasks with low-glucose DMEM-containing 10\% fetal bovine serum (FBS), penicillin, and streptomycin (complete medium), and were incubated in $5 \% \mathrm{CO}_{2}$ in a $37^{\circ} \mathrm{C}$. After 2 days, the medium was gently replaced with fresh medium. Upon reaching $80-90 \%$ confluency, cells were harvested using $0.2 \%$ trypsin-EDTA, as the first passage (P1).

Human MSCs were identified by the specific cell surface markers, including CD105(+), CD73(+), CD29(+), CD90(+), CD44(+), CD45(-), CD31(-), CD34(-), and HLA-DR(-).

Their capability of differentiating into adipocytes and osteoblasts is also examined. In short, $1 \times 10^{5}$ MSCs were cultured in 12-well plate. When it reaches $80-90 \%$ confluency, for adipogenesis, the culture medium was replaced with high-glucose DMEM-containing 10\% FBS (complete medium) with $0.5 \mathrm{mM}$ isobutylmethylxanthine, $50 \mu \mathrm{M}$ indomethacin, and $0.5 \mu \mathrm{M}$ dexamethasone. Fresh medium was changed every 3 days. After 2 weeks, Oil red $\mathrm{O}$ staining solution was used to reveal lipid accumulations. For osteogenesis, the cells were cultured in complete medium with $100 \mathrm{nM}$ dexamethasone, $2 \mathrm{mM} \beta$-glycerophosphate, and $50 \mu \mathrm{M}$ ascorbate-2-phosphate. Fresh medium was changed every 3 days for 3-4 weeks. Calcium deposition was stained using 2\% Alizarin Red S solution. Control medium was high-glucose DMEM containing $10 \%$ FBS (complete medium).

\section{Animals}

$\mathrm{BALB} / \mathrm{c}$ and $\mathrm{C} 57 \mathrm{BL} / 6$ mice were purchased from Shanghai Laboratory Animal Center of the Chinese Academy of Sciences, Shanghai, China, and maintained under specific pathogen-free conditions. All procedures were approved by the Institutional Animal Care and Use Committee of the Institute of Health Sciences, Shanghai Institutes for Biological Sciences of Chinese Academy of Sciences.

\section{Transfections with shRNA/siRNA}

Human MSCs were plated on 12-well plate at the density of $5 \times 10^{4}$ per well, and were treated with $5 \mu \mathrm{g} / \mathrm{ml}$ Polybrene (Santa Cruz Biotechnology) along with $10 \mu \mathrm{l}$ IDO or TSG-6 
Table 1 Primers used for real-time q-PCR

\begin{tabular}{ll}
\hline Primer name & Sequence $\left(5^{\prime}-3^{\prime}\right)$ \\
\hline Human $\beta$-actin & TTGCCGACAGGATGCAGAAGGA
\end{tabular}

Human $\beta$-actin TTGCCGACAGGATGCAGAAGGA

Human IDO

Human TSG-6

Human KAT I

Human KAT II

Human 3-HAO

Human KMO

Human KYNU

Human AhR

Human CYP1A1

Human CYP1B1

Human ANGPT1

Human FGF7

Human GPR35

Human GRIN1

Human GRIN2A

Human GRIN2B

Human GRIN3A

Human $\alpha 7 \mathrm{nAChR}$

Human AMPAR1

Human AMPAR2

Human AMPAR3

Human AMPAR4

Human KainateR1 AGGTGGACAGCGAGGCCAGGAT GCCCTTCAAGTGTTTCACCAA CCAGCCAGACAAATATATGCGA TGTCTGTGCTGCTGGATGGAT TGTGGGTTGTAGCAATAGGCAT GTCGTCCTGTGTTTGTGTCCCT GCTTTGGTGCGTGATGTGAA TGGCAGCCAACAAGGTCTTT CCCACTTTCATCACTGGCAAC CCAGGAAGGACTATCACATCGA TATCTCTCCCTGCCGAATGAC TGCGAGCACATGTCAACTCAA TTTGCCAATGCCAACGCT TTGGCTTTGATCTAGCACATGC CATGAATGAAGGCACCAGCA ATTGTGCCGAGTCCCATATC AAGCAGGCGTGCATTAGACT CTTGGACCTCTTTGGAGCT GACCTGCCAATCACTGTG GACGCCTTTATCCTCTCTGCG ACGACCTGATCCAATTCTGCC AGAACCTTCAAGGCTTGGTTAC GGTGGTAGCTCTGTTTAATTGCT TCCTGCCAACTTTGCTCTACA CAGGGCTGGAACAGTTCACAT CTCCCTGCGAGACACCTCA CTGATGCTCATGTACCTGTTGG ACCCCAAGATCGTCAACATTG GGCTAACTAGGATGGCGTAGA TCATGCAGGATTATGACTGGCA TGTGGTCTTGACGAAGCTGAT TCTGACCGGAAGATCCAGGG TCCATGATGTTGAGCATTACGG CGGGACGCCCTCCTATTTG CCACGGTATGGCACACACT GCTGGTCAAGAACTACAATCCC CTCATCCACGTCCATGATCTG TGCTTTGTCGCAACTCACAGA GGCATAGACTCCTTTGGAGAAC TGCATACCTCTATGACAGTGACA AGAATTACACGCCGTTCCTTT ACCATCAGCATAGGTGGACTT GGTTGGTGTTGTATAACTGCACG CAGCGCCTTACATATCTCCCT GAAGGTCTTAGTTGCAGCACA TGCTCTCGAAGTTCCACACAT
shRNA lentiviral particles (Santa Cruz Biotechnology). The same amount of control shRNA lentiviral particles-A (Santa Cruz Biotechnology) was also transfected into MSCs as control. The culture medium was refreshed $24 \mathrm{~h}$ after transfection. Puromycin (Sigma-Aldrich) was employed to select stable knockdown cells for at least three passages.

For IDO and KAT II knockdown, human MSCs were transfected with IDO siRNA (Biomics Biotechnologies Co., Ltd) or KAT II siRNA (Santa Cruz Biotechnology) using Nucleofection $^{\mathrm{TM}}$ (Lonza) according to the manufacturer's protocols. In brief, every $1 \times 10^{6}$ cells were resuspended in $100 \mu \mathrm{l}$ electrotransfection solution, which contains $82 \mu \mathrm{l}$ Human MSC Nucleofector Solution (Lonza) and $18 \mu \mathrm{l}$ Supplement (Lonza), and then were transfected with 120 pmol IDO or KAT II siRNA using the U-23 program (Lonza). After transfection, cells were plated to a six-well plate at the density of $5 \times 10^{5}$ cells per well. After $48 \mathrm{~h}$, cells were treated with indicated stimulations. IDO siRNA sequence is: 5'-GAACGGGACACUUUGCUAAdTdT-3'.

\section{Murine model of LPS-induced ALI}

Female BALB/c mice (8-10-week old) were treated with either $20 \mu \mathrm{g}$ LPS (Sigma-Aldrich) from Escherichia coli (serotype 0111:B4) in 50 $\mu \mathrm{l}$ saline or an equal volume of saline as vehicle control, using intranasal insufflation while anesthetized with tribromoethanol (Sigma-Aldrich). Human MSCs $\left(2.5 \times 10^{5}\right.$ in $200 \mu \mathrm{l}$ PBS $)$ or $25 \mu \mathrm{g}$ of recombinant human TSG-6 protein (R\&D Systems) were administered through intravenous injection 4 and $28 \mathrm{~h}$ after LPS administration, while PBS was injected as a control. Mice were killed $48 \mathrm{~h}$ after LPS exposure. To obtain BAL fluid, lungs were washed three times with $1 \mathrm{ml}$ PBS through i.t. cannulae. The total cell number in BAL fluid was counted and neutrophil numbers were determined by immunofluorescence staining and flow cytometry (BD FACS Calibur, BD Bioscience) as follows. Cells were pre-incubated with anti-CD16/CD32 (eBioscience) to block Fc receptors, and then stained with anti-CD45, anti-CD11b, anti-Ly-6G (clone 1A8), and anti-Ly-6C (eBioscience) for $20 \mathrm{~min}$. Neutrophils were identified by the phenotype, CD45 ${ }^{+}$CD $11 b^{+}$Ly-6G ${ }^{+}$Ly-6C ${ }^{\text {med }}$.

\section{Histological analysis of lungs}

Isolated lung tissues were fixed in $4 \%$ paraformaldehyde, embedded in paraffin, and cut into 4- $\mu \mathrm{m}$-thick sections, and then stained with hematoxylin and eosin. Infiltrating neutrophils were revealed by immunohistochemistry, using anti-mouse Ly-6G/Ly-6C (Gr-1) antibody (BioLegend), followed by HRP-linked anti-rat secondary antibody (Fuzhou Maixin Biotech Co., Ltd) and diaminobenzidin 
Table 1 (continued)

\begin{tabular}{ll}
\hline Primer name & Sequence $\left(5^{\prime}-3^{\prime}\right)$ \\
\hline Human KainateR2 & CCTGTGCTGTCTTCATACACC \\
& TTCAGGCGCACCGTTAAACT \\
Human KainateR3 & TTCGACCATTGGGCCAGATT \\
Human KainateR4 & GGTTCACGTAGAAGGTGTCCT \\
& CAAGGCCAAGGTCGAAGTG \\
Human KainateR5 & CTCCACAGATGTTGCTGATGAT \\
& CCACCGTGAGCCATATCTGTG \\
& CGCGAAGCGAAGGTACTGAA \\
\hline
\end{tabular}

(Fuzhou Maixin Biotech Co., Ltd.). Images were taken with Zeiss AxioObserver.Z1 microscope. Three mice were included for each group in independent experiments. More than three fields from each mouse were selected and the images are representative for each experiment repeats.

\section{Murine model of zymosan-induced peritonitis}

To prepare a suspension of Zymosan A (Sigma-Aldrich), dry powder was resuspended in PBS at $1 \mathrm{mg} / \mathrm{ml}$, autoclaved at $121^{\circ} \mathrm{C}$ for $15 \mathrm{~min}$, washed three times with ice-cold PBS using centrifugation at $300 \mathrm{~g}$ for $10 \mathrm{~min}$ at $4{ }^{\circ} \mathrm{C}$, and then resuspended in PBS at $1 \mathrm{mg} / \mathrm{ml}$. Female C57BL/6 mice (8-10 weeks old) were anesthetized with tribromoethanol, and then injected i.p. with $1 \mathrm{ml}$ of zymosan A suspension, followed by i.p. injection of human MSCs $\left(3 \times 10^{6}\right.$ cells in $125 \mu \mathrm{l}$ PBS), or $30 \mu \mathrm{g}$ rhTSG-6 protein dissolved in $125 \mu \mathrm{l}$ PBS. An equal volume of PBS was injected as control. After $12 \mathrm{~h}$, mice were killed, and peritoneal exudates were collected by lavage with $10 \mathrm{ml}$ of sterile PBS. Cells in peritoneal lavage were enumerated and then cell phenotype was determined by immunofluorescence staining for CD11b, Ly-6C, Ly-6G, and F4/80 (eBiosciences), as described above.

\section{Immunosuppression by MSCs}

Human PBMCs were purified from fresh whole blood using Ficoll (GE Healthcare) density gradient isolation as previously described [52]. PBMC proliferation was determined by CFSE (Sigma-Aldrich) staining and flow cytometry, as follows: freshly isolated PBMCs $\left(2 \times 10^{7}\right.$ cells $)$ in $1 \mathrm{ml}$ of PBS containing $0.1 \%$ BSA were incubated with $5 \mu \mathrm{M}$ CFSE for $10 \mathrm{~min}$ in a $37^{\circ} \mathrm{C}$ water bath, with vortexing every 2 min. Staining was terminated by addition of $1 \mathrm{ml}$ of FBS at $4{ }^{\circ} \mathrm{C}$ for $5 \mathrm{~min}$. Cells were then washed twice with PBS containing 5\% FBS. After washing, PBMCs were incubated with or without MSCs at the ratio of 10:1 (PBMC:MSC). After $48 \mathrm{~h}, \mathrm{PBMCs}$ were collected and CFSE levels were measured by flow cytometry.

\section{Gene expression analysis}

Total cellular RNA was isolated using RNAprep pure Cell/ Bacterial Kit (Tiangen Biotech). First-strand cDNA was synthesized using PrimeScript ${ }^{\mathrm{TM}}$ RT Master Mix (Takara Biotechnology). The mRNA expression levels were assayed by real-time qPCR (7900 HT Fast Real-Time PCR system, Applied Biosystems) using FastStart Universal SYBR Green Master (Roche). Primer sequences are listed in Table 1.

\section{TSG-6 ELISA}

TSG-6 protein level in the supernatant of human MSCs cultured with inflammatory cytokines was measured by ELISA as previously described [17]. Briefly, a 96-well plate was coated with $50 \mu \mathrm{l}$ of $10 \mu \mathrm{g} / \mathrm{ml}$ TSG-6 antibody (clone A38.1.20, Santa Cruz Biotechnology) overnight, in a coating buffer of $0.2 \mathrm{M}$ sodium bicarbonate ( $\mathrm{pH} 9.2$ ). The plate was washed with PBS, blocked with $0.25 \%$ BSA and $0.05 \%$ Tween 20 in PBS for $30 \mathrm{~min}$, and again washed with PBS. Samples $(50 \mu \mathrm{l})$ and a standard of human recombinant TSG6 protein (R\&D Systems) in blocking buffer were added and incubated at $4{ }^{\circ} \mathrm{C}$ overnight. Then, the plate was washed with PBS, followed by addition of biotinylated anti-human TSG-6 antibody ( $50 \mu \mathrm{l}$ of $0.5 \mu \mathrm{g} / \mathrm{ml}$; R\&D Systems) and incubated for $3 \mathrm{~h}$ at room temperature. After washing with PBS, streptavidin-HRP (50 $\mu \mathrm{l}$; R\&D Systems) was added for $30 \mathrm{~min}$ at room temperature, and developed using substrate solutions (R\&D Systems).

\section{Liquid chromatography-mass spectrometry analysis}

Supernatant from MSC cultures was collected and filtered $(0.22 \mu \mathrm{m}$; Merck Millipore) to remove cell debris. Samples were 1:50 diluted by formic acid, and analyzed by hybrid mass spectrometer (Orbitrap Velos Pro, Thermo Fisher) as previously described [53].

\section{Immunoblotting assays}

Proteins were extracted from cells using RIPA Lysis Buffer (Merck Millipore) supplemented with protease inhibitor (Roche) and $1 \mathrm{mM}$ PMSF (Sigma-Aldrich), and then separated by SDS-PAGE and transferred to Nitrocellulose Blotting Membranes (GE Healthcare Life Sciences). Antibody used were against IDO (clone 10.1) from Millipore, AhR from Sigma-Aldrich, and GAPDH and laminB1 from Cell Signaling Technology.

\section{Nuclear and cytoplasmic protein extraction}

Nuclear and cytoplasmic protein isolation was performed using the nuclear and cytoplasmic extraction reagent 
(Thermo Fisher) according to the manufacturer's instructions. Briefly, harvested cells were washed by PBS, left to dry, and added with CER I reagent (Thermo Fisher). Cells were then vortexed vigorously and incubated on ice for 10 min. Then, the CER II reagent (Thermo Fisher) was added, followed by vortexing, incubating on ice, and centrifuging at maximum speed for $5 \mathrm{~min}$. The supernatant contains the cytoplasmic extract. The left pellet was then resuspended by NER reagent (Thermo Fisher) and vortexed on the highest setting for $15 \mathrm{~s}$ every $10 \mathrm{~min}$, for a total of $40 \mathrm{~min}$ before centrifuging again at maximum speed for $10 \mathrm{~min}$. The supernatant was the nuclear extract. Protein concentration was determined using the Bradford protein assay reagent (Bio-Rad). Normalized protein samples went through immunoblotting assay.

\section{ChIP assay}

Chromatin from MSCs was fixed and immunoprecipitated using the ChIP assay kit (Millipore) according to the manufacturer's protocols. The average size of sonicated DNA fragments that were subjected to immunoprecipitation was $200 \mathrm{bp}$ as detected by ethidium bromide gel electrophoresis. The purified chromatin was immunoprecipitated with or without 10 $\mu \mathrm{g} / \mathrm{ml}$ anti-AhR (clone RPT9, Abcam). The amount of the specific DNA sequence was determined by real-time PCR. The primers were 5'-ATGCAAATGAACACAGAAGGGTATC-3' and 5'-GCAAAACCTTCCCATAGTCTTTCC-3'.

\section{Immunofluorescence assay}

MSCs were seeded on eight-chamber slide (Thermo Fisher) at the density of $1 \times 10^{4}$ cells per chamber. After indicated treatment, cells were fixed with methanol for $5 \mathrm{~min}$, and followed by permealization with $0.1 \%$ Triton X-100 for 10 min. After PBS washing, cells were blocked with $1 \%$ BSA, $22.52 \mathrm{mg} / \mathrm{ml}$ glycine, and $0.1 \%$ Tween 20 in PBS for 30 $\min$. The cells were then subjected to immunofluorescence staining with $10 \mu \mathrm{g} / \mathrm{ml}$ anti-AhR (clone RPT9, Abcam) overnight at $4{ }^{\circ} \mathrm{C}$. On the next day, cells were washed with $0.1 \%$ Tween 20 in PBS (PBST) and incubated with Goat anti-Mouse IgG $(\mathrm{H}+\mathrm{L})$ Cross-Adsorbed Secondary Antibody, Alexa Fluor 488 (Thermo Fisher) for $1 \mathrm{~h}$ at room temperature. After PBST washing, cells were counterstained with $1 \mu \mathrm{g} / \mathrm{ml}$ Hoechst (Thermo Fisher) for $1 \mathrm{~min}$ at room temperature. Images were taken with Zeiss AxioObserver Z1 microscope. More than three fields from each treatment group were selected, and the images are representative for each experiment repeats.

\section{Statistical analysis}

Data values are presented as means \pm SEM. Significance was assessed by Student's $t$-test.
Acknowledgments This work was supported by grants from the National Natural Science Foundation of China (81530043, 81330046), the Ministry of Science and Technology of China (2015CB964400), the Suzhou Science and Technology Program (SZS201616), the Youth Innovation Promotion Association research fund from the Chinese Academy of Sciences (2060206), Shanghai Municipal Key Projects of Basic Research (12JC1409200), Shanghai Rising-Star Program (14QA1404200), and the Department of Science and Technology of Jiangsu Province research fund (BE2016671).

Authors' contributions G.W. designed the study, performed experiments, analyzed data, and wrote the manuscript. K.C. performed animal experiments and edited the manuscript. K.L., Y.X., and F.L. performed animal experiments. Y.H. performed histological analysis. A.I.R. edited the manuscript. A.B.R. provided feedback of the manuscript. Y.W. and Y.S. edited the manuscript and supervised the study.

\section{Compliance with ethical standards}

Competing interests The authors declare that they have no competing financial interest.

Open Access This article is licensed under a Creative Commons Attribution-NonCommercial-NoDerivatives 4.0 International License, which permits any non-commercial use, sharing, distribution and reproduction in any medium or format, as long as you give appropriate credit to the original author(s) and the source, and provide a link to the Creative Commons license. You do not have permission under this license to share adapted material derived from this article or parts of it. The images or other third party material in this article are included in the article's Creative Commons license, unless indicated otherwise in a credit line to the material. If material is not included in the article's Creative Commons license and your intended use is not permitted by statutory regulation or exceeds the permitted use, you will need to obtain permission directly from the copyright holder. To view a copy of this license, visit http://creativecommons.org/licenses/by-nc-nd/4.0/.

\section{References}

1. Friedenstein, A. J., Chailakhyan, R. K., Latsinik, N. V., Panasyuk, A. F. \& Keiliss-Borok, I. V. Stromal cells responsible for transferring the microenvironment of the hemopoietic tissues. Cloning in vitro and retransplantation in vivo. Transplantation 17, 331-340 (1974).

2. Uccelli, A., Moretta, L. \& Pistoia, V. Mesenchymal stem cells in health and disease. Nat. Rev. Immunol. 8, 726-736 (2008).

3. Bernardo, M. E. \& Fibbe, W. E. Mesenchymal stromal cells: sensors and switchers of inflammation. Cell Stem. Cell. 13, 392-402 (2013).

4. Shi, Y., Su, J., Roberts, A. I., Shou, P., Rabson, A. B. \& Ren, G. How mesenchymal stem cells interact with tissue immune responses. Trends Immunol. 33, 136-143 (2012).

5. Shi, Y., Cao, J. \& Wang, Y. Rethinking regeneration: empowerment of stem cells by inflammation. Cell Death Differ. 22, 1891-1892 (2015).

6. Ren, G., Su, J., Zhang, L., Zhao, X., Ling, W. \& L'Huillie, A. et al. Species variation in the mechanisms of mesenchymal stem cell-mediated immunosuppression. Stem Cells 27, 1954-1962 (2009).

7. Su, J., Chen, X., Huang, Y., Li, W., Li, J. \& Cao, K. et al. Phylogenetic distinction of iNOS and IDO function in mesenchymal stem cell-mediated immunosuppression in mammalian species. Cell Death Differ. 21, 388-396 (2014). 
8. Hirata, F. \& Hayaishi, O. Studies on indoleamine 2,3-dioxygenase. I. Superoxide anion as substrate. J. Biol. Chem. 250, 5960-5966 (1975).

9. Munn, D. H. \& Mellor, A. L. Indoleamine 2,3 dioxygenase and metabolic control of immune responses. Trends Immunol. 34, 137-143 (2013).

10. Frumento, G., Rotondo, R., Tonetti, M., Damonte, G., Benatti, U. \& Ferrara, G. B. Tryptophan-derived catabolites are responsible for inhibition of $\mathrm{T}$ and natural killer cell proliferation induced by indoleamine 2,3-dioxygenase. J. Exp. Med. 196, 459-468 (2002).

11. Mezrich, J. D., Fechner, J. H., Zhang, X., Johnson, B. P., Burlingham, W. J. \& Bradfield, C. A. An interaction between kynurenine and the aryl hydrocarbon receptor can generate regulatory T cells. J. Immunol. 185, 3190-3198 (2010).

12. Yan, Y., Zhang, G. X., Gran, B., Fallarino, F., Yu, S. \& Li, H. et al. IDO upregulates regulatory $\mathrm{T}$ cells via tryptophan catabolite and suppresses encephalitogenic $\mathrm{T}$ cell responses in experimental autoimmune encephalomyelitis. J. Immunol. 185, 5953-5961 (2010).

13. DiNatale, B. C., Murray, I. A., Schroeder, J. C., Flaveny, C. A., Lahoti, T. S. \& Laurenzana, E. M. et al. Kynurenic acid is a potent endogenous aryl hydrocarbon receptor ligand that synergistically induces interleukin- 6 in the presence of inflammatory signaling. Toxicol. Sci. 115, 89-97 (2010).

14. Pallotta, M. T. et al. Indoleamine 2,3-dioxygenase is a signaling protein in long-term tolerance by dendritic cells. Nat. Immunol. 12, 870-878 (2011).

15. Choi, H., Lee, R. H., Bazhanov, N., Oh, J. Y. \& Prockop, D. J. Anti-inflammatory protein TSG-6 secreted by activated MSCs attenuates zymosan-induced mouse peritonitis by decreasing TLR2/NF-kappaB signaling in resident macrophages. Blood 118, 330-338 (2011).

16. Danchuk, S., Ylostalo, J. H., Hossain, F., Sorge, R., Ramsey, A. \& Bonvillain, R. W. et al. Human multipotent stromal cells attenuate lipopolysaccharide-induced acute lung injury in mice via secretion of tumor necrosis factor-alpha-induced protein 6. Stem Cell Res. Ther. 2, 27 (2011).

17. Lee, R. H., Pulin, A. A., Seo, M. J., Kota, D. J., Ylostalo, J. \& Larson, B. L. et al. Intravenous hMSCs improve myocardial infarction in mice because cells embolized in lung are activated to secrete the anti-inflammatory protein TSG-6. Cell Stem Cell. 5, 54-63 (2009).

18. Oh, J. Y., Roddy, G. W., Choi, H., Lee, R. H., Ylostalo, J. H. \& Rosa, R. H. Jr et al. Anti-inflammatory protein TSG-6 reduces inflammatory damage to the cornea following chemical and mechanical injury. Proc. Natl Acad. Sci. USA 107, 16875-16880 (2010).

19. Milner, C. M. \& Day, A. J. TSG-6: a multifunctional protein associated with inflammation. J. Cell Sci. 116, 1863-1873 (2003).

20. Dyer, D. P., Thomson, J. M., Hermant, A., Jowitt, T. A., Handel, T. M. \& Proudfoot, A. E. et al. TSG-6 inhibits neutrophil migration via direct interaction with the chemokine CXCL8. $J$. Immunol. 192, 2177-2185 (2014).

21. Lesley, J., English, N. M., Gal, I., Mikecz, K., Day, A. J. \& Hyman, R. Hyaluronan binding properties of a CD44 chimera containing the link module of TSG-6. J. Biol. Chem. 277, 26600-26608 (2002).

22. Shi, Y., Hu, G., Su, J., Li, W., Chen, Q. \& Shou, P. et al. Mesenchymal stem cells: a new strategy for immunosuppression and tissue repair. Cell Res. 20, 510-518 (2010).

23. Lee, J. W., Fang, X., Gupta, N., Serikov, V. \& Matthay, M. A. Allogeneic human mesenchymal stem cells for treatment of E. coli endotoxin-induced acute lung injury in the ex vivo perfused human lung. Proc. Natl Acad. Sci. USA 106, 16357-16362 (2009).
24. Mei, S. H., McCarter, S. D., Deng, Y., Parker, C. H., Liles, W. C. \& Stewart, D. J. Prevention of LPS-induced acute lung injury in mice by mesenchymal stem cells overexpressing angiopoietin 1 . PLoS Med. 4, e269 (2007).

25. Ortiz, L. A., Dutreil, M., Fattman, C., Pandey, A. C., Torres, G. \& Go, K. et al. Interleukin 1 receptor antagonist mediates the antiinflammatory and antifibrotic effect of mesenchymal stem cells during lung injury. Proc. Natl Acad. Sci. USA 104, 11002-11007 (2007).

26. Vecsei, L., Szalardy, L., Fulop, F. \& Toldi, J. Kynurenines in the CNS: recent advances and new questions. Nat. Rev. Drug. Discov. 12, 64-82 (2013).

27. Moroni, F., Cozzi, A., Sili, M. \& Mannaioni, G. Kynurenic acid: a metabolite with multiple actions and multiple targets in brain and periphery. J. Neural. Transm. 119, 133-139 (2012).

28. Murray, I. A., Patterson, A. D. \& Perdew, G. H. Aryl hydrocarbon receptor ligands in cancer: friend and foe. Nat. Rev. Cancer 14, 801-814 (2014).

29. Apetoh, L., Quintana, F. J., Pot, C., Joller, N., Xiao, S. \& Kumar, D. et al. The aryl hydrocarbon receptor interacts with c-Maf to promote the differentiation of type 1 regulatory $\mathrm{T}$ cells induced by IL-27. Nat. Immunol. 11, 854-861 (2010).

30. Stockinger, B., Di Meglio, P., Gialitakis, M. \& Duarte, J. H. The aryl hydrocarbon receptor: multitasking in the immune system. Annu. Rev. Immunol. 32, 403-432 (2014).

31. Metghalchi, S., Ponnuswamy, P., Simon, T., Haddad, Y., Laurans, L. \& Clement, M. et al. Indoleamine 2,3-dioxygenase fine-tunes immune homeostasis in atherosclerosis and colitis through repression of interleukin-10 production. Cell Metab. 22, 460-471 (2015).

32. Pearce, E. L., Poffenberger, M. C., Chang, C. H. \& Jones, R. G. Fueling immunity: insights into metabolism and lymphocyte function. Science 342, 1242454 (2013).

33. Grohmann, U., Bianchi, R., Belladonna, M. L., Silla, S., Fallarino, F. \& Fioretti, M. C. et al. IFN-gamma inhibits presentation of a tumor/self peptide by CD8 alpha- dendritic cells via potentiation of the CD8 alpha+subset. J. Immunol. 165, 1357-1363 (2000).

34. Hwu, P., Du, M. X., Lapointe, R., Do, M., Taylor, M. W. \& Young, H. A. Indoleamine 2,3-dioxygenase production by human dendritic cells results in the inhibition of T cell proliferation. $J$. Immunol. 164, 3596-3599 (2000).

35. Munn, D. H., Shafizadeh, E., Attwood, J. T., Bondarev, I., Pashine, A. \& Mellor, A. L. Inhibition of T cell proliferation by macrophage tryptophan catabolism. J. Exp. Med. 189, 1363-1372 (1999).

36. Schwarcz, R., Bruno, J. P., Muchowski, P. J. \& Wu, H. Q. Kynurenines in the mammalian brain: when physiology meets pathology. Nat. Rev. Neurosci. 13, 465-477 (2012).

37. Varga, G., Erces, D., Fazekas, B., Fulop, M., Kovacs, T. \& Kaszaki, J. et al. N-Methyl-D-aspartate receptor antagonism decreases motility and inflammatory activation in the early phase of acute experimental colitis in the rat. Neurogastroen Motil. 22, e268 (2010).

38. Wang, J., Simonavicius, N., Wu, X., Swaminath, G., Reagan, J. \& Tian, H. et al. Kynurenic acid as a ligand for orphan $\mathrm{G}$ proteincoupled receptor GPR35. J. Biol. Chem. 281, 22021-22028 (2006).

39. Ware, L. B. \& Matthay, M. A. The acute respiratory distress syndrome. N. Engl. J. Med. 342, 1334-1349 (2000).

40. Wheeler, A. P. \& Bernard, G. R. Acute lung injury and the acute respiratory distress syndrome: a clinical review. Lancet 369, 1553-1564 (2007).

41. Wang, C. Y., Calfee, C. S., Paul, D. W., Janz, D. R., May, A. K. $\&$ Zhuo, H. et al. One-year mortality and predictors of death among hospital survivors of acute respiratory distress syndrome. Intens. Care Med. 40, 388-396 (2014). 
42. Horita, N., Hashimoto, S., Miyazawa, N., Fujita, H., Kojima, R. \& Inoue, M. et al. Impact of corticosteroids on mortality in patients with acute respiratory distress syndrome: a systematic review and meta-analysis. Internal Med. 54, 1473-1479 (2015).

43. Iwata, K., Doi, A., Ohji, G., Oka, H., Oba, Y. \& Takimoto, K. et al. Effect of neutrophil elastase inhibitor (sivelestat sodium) in the treatment of acute lung injury (ALI) and acute respiratory distress syndrome (ARDS): a systematic review and metaanalysis. Internal Med. 49, 2423-2432 (2010).

44. Anzueto, A., Baughman, R. P., Guntupalli, K. K., Weg, J. G., Wiedemann, H. P. \& Raventos, A. A. et al. Aerosolized surfactant in adults with sepsis-induced acute respiratory distress syndrome. Exosurf Acute Respiratory Distress Syndrome Sepsis Study Group. N. Engl. J. Med. 334, 1417-1421 (1996).

45. Dellinger, R. P., Zimmerman, J. L., Taylor, R. W., Straube, R. C., Hauser, D. L. \& Criner, G. J. et al. Effects of inhaled nitric oxide in patients with acute respiratory distress syndrome: results of a randomized phase II trial. Inhaled Nitric Oxide in ARDS Study Group. Crit. Care Med. 26, 15-23 (1998).

46. Li, C., Bo, L., Liu, W., Lu, X. \& Jin, F. Enteral immunomodulatory diet (omega-3 fatty acid, gamma-linolenic acid and antioxidant supplementation) for acute lung injury and acute respiratory distress syndrome: an updated systematic review and meta-analysis. Nutrients 7, 5572-5585 (2015).

47. National Heart, L., Blood Institute Acute Respiratory Distress Syndrome Clinical Trials N, Matthay, M. A., Brower, R. G., Carson, S. \& Douglas, I. S. et al. Randomized, placebo-controlled clinical trial of an aerosolized beta(2)-agonist for treatment of acute lung injury. Am. J. Respir. Crit. Care Med. 184, 561-568 (2011).

48. National Heart L, Blood Institute ACTN, Truwit, J. D., Bernard, G. R., Steingrub, J. \& Matthay, M. A. et al. Rosuvastatin for sepsis-associated acute respiratory distress syndrome. N. Engl. J. Med. 370, 2191-2200 (2014).

49. Paine, R. 3rd, Standiford, T. J., Dechert, R. E., Moss, M., Martin, G. S. \& Rosenberg, A. L. et al. A randomized trial of recombinant human granulocyte-macrophage colony stimulating factor for patients with acute lung injury. Crit. Care Med. 40, 90-97 (2012).

50. Matthay, M. A., Goolaerts, A., Howard, J. P. \& Lee, J. W. Mesenchymal stem cells for acute lung injury: preclinical evidence. Crit. Care Med. 38, S569-S573 (2010).

51. Zheng, G., Huang, L., Tong, H., Shu, Q., Hu, Y. \& Ge, M. et al. Treatment of acute respiratory distress syndrome with allogeneic adipose-derived mesenchymal stem cells: a randomized, placebocontrolled pilot study. Resp. Res. 15, 39 (2014).

52. Ruitenberg, J. J., Mulder, C. B., Maino, V. C., Landay, A. L. \& Ghanekar, S. A. VACUTAINER CPT and Ficoll density gradient separation perform equivalently in maintaining the quality and function of PBMC from HIV seropositive blood samples. BMC Immunol. 7, 11 (2006).

53. Wilson, I. D., Nicholson, J. K., Castro-Perez, J., Granger, J. H., Johnson, K. A. \& Smith, B. W. et al. High resolution "ultra performance" liquid chromatography coupled to oa-TOF mass spectrometry as a tool for differential metabolic pathway profiling in functional genomic studies. J. Proteome Res. 4, 591-598 (2005). 